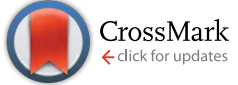

Cite this: RSC Adv., 2015, 5, 101221

Received 17th September 2015 Accepted 16th November 2015

DOI: 10.1039/c5ra19197a

www.rsc.org/advances

\section{Spectroscopic chemical insights leading to the design of versatile sustainable composites for enhanced marine application $\uparrow$}

\author{
Agnieszka S. Dzielendziak, ${ }^{a}$ James I. R. Blake, ${ }^{a}$ Richard Bounds, ${ }^{b}$ Karl A. Wilkinson, ${ }^{b}$ \\ Marina Carravetta, ${ }^{\mathrm{b}}$ Alan R. Chambers, ${ }^{\mathrm{a}}$ Chris-Kriton Skylaris ${ }^{\mathrm{b}}$ and Robert Raja*b
}

The viability of a novel sustainable polymeric composite material, based on photocurable linseed oil resin was explored, with a view to exploiting its potential in marine environments. The study focused on a UV-curable resin subjected to setting through photoinitiated cationic polymerisation. Deployment of heterogeneous solid catalysts, containing isolated Brønsted acid centres, further improved the efficiency of cationic polymerisation, leading to enhanced thermal stability and water resistance. These features are highly desirable in the design of composite resins for marine applications. A wide range of spectroscopic, calorimetric and thermogravimetric methods as well as computational simulations have been employed to study the physico-chemical characteristics of the resin and its resistance to black and grey waste, UV resistance and hygrothermal ageing. The findings have revealed that, unlike conventional epoxy resins, the ELO resin demonstrated no decrease in glass transition temperature, $T_{\mathrm{g}}$, despite having been exposed to different methods of ageing. In addition, the water molecules that are absorbed by the resin during hygrothermal ageing have been found to be structurally-bound through hydrogen bonding, which is supported by initial computational studies. The structure-property correlations that have been derived help to better understand the ageing process, which could be beneficial in predicting the lifetimes of these sustainable polymeric composite materials and consequently developing novel chemical methods for improving their durability and stability.

\section{Introduction}

Given the legislative requirements on the reduction of the use of fossil fuels for composite manufacturing, there is a growing

${ }^{a}$ Faculty of Engineering and the Environment, University of Southampton, Highfield, SO17 1BJ, UK. Fax: +44 (0)2380597744; Tel: +44 (0)2380597772

${ }^{b}$ Faculty of Natural and Environmental Sciences, School of Chemistry, University of Southampton, Highfield, SO17 1BJ, UK. E-mail: r.raja@soton.ac.uk

$\dagger$ Electronic supplementary information (ESI) available: Epoxidation of linseed oil, comparison of glass transition temperatures of differently treated samples, proposed mechanism of ELO polymerisation initiation, proposed mechanism of ELO polymerisation propagation, molecular dynamics simulations. See DOI: 10.1039/c5ra19197a interest in the long-term structural and improved performance of sustainable alternatives to conventional fibers and resins. ${ }^{1-3}$ Whilst the shipping industry is the most efficient mode of transport, and growing year by year, it contributes around $3 \%$ of global $\mathrm{CO}_{2}$ emissions. ${ }^{4}$ A commonly observed tendency in the marine industry is the conscious effort to reduce the overall mass of ships through the use of novel polymeric materials. This should potentially lead to a decrease of resistance and lower fuel consumption, with a concomitant increase in the cargo vessels' carrying capability. With smaller fuel consumption come lower emission levels of $\mathrm{CO}_{2}$ and other pollutants, which makes the ships more environmentally efficient and sustainable.

The marine industry is one of the largest consumers of composite materials that are derived from polymer resins and the marine environment represents a unique challenge for sustainable composites. According to Composite Insights, ${ }^{5}$ the demand for composite polymeric materials in the global marine-composites industry is expected to grow $5.8 \%$ per year between 2013 and 2018. This represents an opportunity for the maritime sector to realise the potential for polymer-composites application, both from a material and chemical perspective. It is therefore vital for the physical and chemical properties of these sustainable composite materials to be well understood at a molecular level in order to meet the stringent requirement of operation in the harsh marine environment. ${ }^{6}$

In order to ensure safe performance of sustainable composite structures it is necessary for the users to have confidence in the material properties, processability, and their through-life capacity to sustain loads and retain stability (Fig. 1).

Failure mechanisms during service can be identified but the root cause behind material degradation and the chemistry associated with these processes remains unclear., ${ }^{8,9}$

Malmstein et al. ${ }^{8}$ reported that after $20+$ weeks of hygrothermal ageing, glass fibre/linseed oil-based resin specimens lost $72 \%$ of their dry strength, which may be caused by insufficient level of resin curing (polymerisation) and chemical 


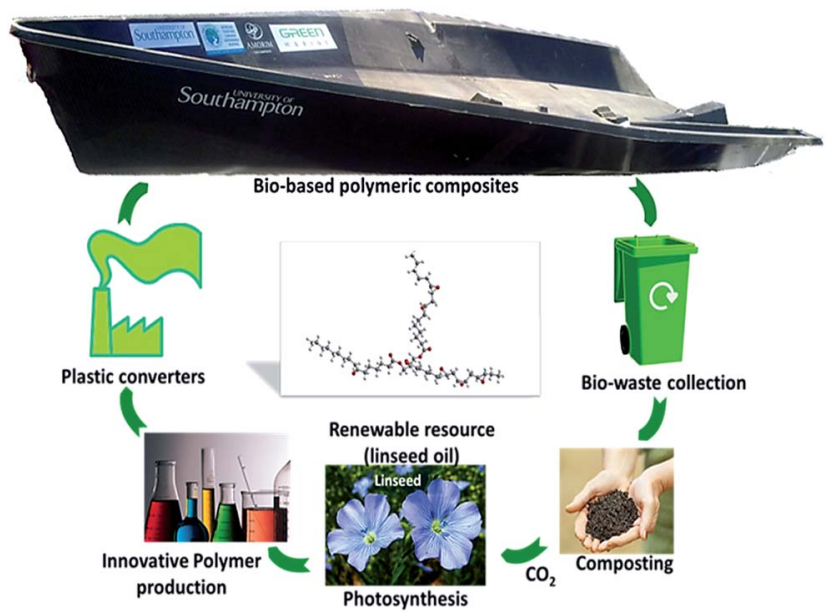

Fig. 1 The lifecycle of sustainable composite materials derived from linseed oil.7

reactions between water and linseed oil resin (polymer matrix) and/or fibre-matrix interface (ageing processes). They also noted that the physico-chemical properties of glass/ conventional epoxy resin were subjected to constant degradation, while the moisture content remained fairly constant, indicating chemical degradation of the composite material. It was apparent $t^{8}$ that the glass/linseed resin degraded rapidly during the first 2 weeks of immersion, but after 4 weeks and until the end of the testing period, it suffered no further degradation.

In recent years fibres derived from plant-based resources ${ }^{10-13}$ have received much attention and, as a result, a substantial amount of research has been conducted in order to rationalize and quantify their properties. However, in stark contrast, very little attention has been devoted to understanding the physicochemical characteristics of sustainable resins, with a view to enhancing their potential impact. To the best of our knowledge there is very little information in the open literature from a design-application perspective and hence polymeric composite materials utilizing them are not widely used or even considered as a technically viable option. This work is aimed at achieving a better understanding of the underlying chemistry principles behind the degradation process in harsh marine environments, as has been acquired to date for conventional epoxy ${ }^{14,15}$ resins, which is one of the most widely used in the marine industry sector. Only a combined, multiscale and multidisciplinary approach, involving the study of both the physical and chemical attributes, that is aligned at addressing structure-property relationships, will help bridge the gap between the engineering and chemistry aspects of sustainable polymeric composites.

Linseed oil (see Scheme 1) is a drying oil and, in its polymerised form, has been used for centuries as a protective coating. ${ }^{16}$ In recent years, it has been successfully employed, albeit in small-scale, as a composite coating material in boat building applications $^{17}$ (Fig. 1). With a number of recent advances ${ }^{18-21}$ substantiating its potential as an effective coating material, its use

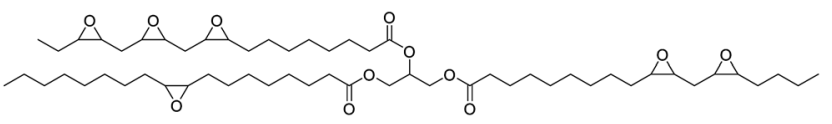

Scheme 1 Chemical structure of epoxidised linseed oil (ELO).

in the maritime sector is likely to witness further growth, which makes it a good model system for the current study.

Sharma et $a .^{22}$ reported that linseed oil is composed of about $53 \%$ linolenic acid, $18 \%$ oleic acid, $15 \%$ linoleic acid, $6 \%$ palmitic acid and $6 \%$ stearic acid; it can be polymerized by cationic, thermal, free radical polymerisation, as well as by oxidative polymerisation. ${ }^{23}$ It has been further reported that, on average, an epoxidised triglyceride of linseed oil has a molecular weight of about $950 \mathrm{~g}$ mol$^{-1}$ and contains about five epoxy groups. ${ }^{24}$ Epoxidised linseed oil (ELO) along with some its derivatives has been investigated using analytical methods (for instance properties of thermosetting resin based on epoxidised linseed oil have been reported by N. Supanchaiyamat et al. ${ }^{25}$ ), but, to the best of our knowledge, this is the first report outlining the physico-chemical attributes of UV-curable epoxidised linseed-oil-based resins, with a view to their potential implementation as a sustainable composite material.

In this study, a combination of spectroscopic techniques (Fourier Transform Infrared spectroscopy (FT-IR), solid-state Nuclear Magnetic Resonance $\left({ }^{13} \mathrm{C}\right.$ NMR $\left.)\right)$ and experimental gravimetric analytical methods (Differential Scanning Calorimetry (DSC), Thermogravimetric analysis (TGA)) have been astutely used with a view to understanding the underlying chemical processes and mechanisms of sustainable composite ageing. In the case of UV cured resins, which in their future lifecycles will be exposed to additional quantities of UV radiation (unavoidable in marine applications), it is of paramount importance to systematically monitor the level of curing; and secondly to find the point from which the additional amount of UV light is causing damage to the polymer (the boundary between UV-curing and UV ageing). With the above in mind, a range of samples have been exposed to UV radiation for different periods of time and consequently analysed via FT-IR, DSC and TGA. The maximum level of curing that is likely to be achieved is also influenced by the efficiency of the epoxidation (see the ESI Scheme S1†); and it was therefore necessary to monitor liquid samples by FT-IR for completeness within this study.

Other physical and chemical properties that are prerequisites for future marine deployment such as resistance to fresh and sea water (hence the resin could be used as a building material for both boat exterior and interior applications) and the resistance to black (any waste from toilets or urinals) ${ }^{26,27}$ and grey waste (wastewater that has been used for washing, laundering, bathing, etc. $)^{26,27}$ were also considered during this investigation.

\section{Experimental}

\section{Materials}

Epoxidised linseed oil (ELO) based UV curable (via photoinitiated cationic polymerisation) resin was obtained from 
sustainable composites. ${ }^{17}$ The resin consists of $95 \%$ of epoxidised linseed oil, $\leq 2.5 \%$ of undisclosed photoinitiator and $\leq 2.5 \%$ propylene carbonate (CAS: 108-32-7).

Standard buffer solution $\mathrm{pH} 4$ (phthalate) stabilised with 10 ppm mercury(II) chloride and standard buffer solution $\mathrm{pH} 7$ (phosphate) stabilised with 10 ppm mercury(II) chloride have been purchased from Fisher Scientific. Buffer solution $\mathrm{pH} 10$ has been purchased from Eutech Instruments. H-ZSM5 $\left(\mathrm{SiO}_{2}\right)$ $\mathrm{Al}_{2} \mathrm{O}_{3}$ mole ratio $\left.=30\right)$ and Zeolite-Y $\left(\mathrm{SiO}_{2} / \mathrm{Al}_{2} \mathrm{O}_{3}\right.$ mole ratio $=$ 30) have been purchased from Zeolyst. Pripol 1009 was kindly supplied by Croda.

\section{Sample preparation}

For the preparation of pure samples, the resin was mixed at $40{ }^{\circ} \mathrm{C}$ using magnetic stirrer for 20 minutes prior to UV curing.

For the preparation of zeolite enhanced samples, firstly catalyst (ZSM-5 and Zeolite $\mathrm{Y}, \mathrm{Si} / \mathrm{Al}=30, \mathrm{NH}_{4}{ }^{+}$form) was converted into the protonic $\left(\mathrm{H}^{+}\right)$form by calcination at $600{ }^{\circ} \mathrm{C}$ for 16 hours under a flow of air. The resulting zeolite was then mixed with resin (catalyst concentration: $2 \mathrm{wt} \%$ ) at $40{ }^{\circ} \mathrm{C}$ for 30 minutes. After degasing in a vacuum chamber for 30 minutes, samples were UV cured at ambient temperature. Samples with the addition of $10 \mathrm{wt} \%$ of the bio-derived crosslinker (Pripol 1009) were mixed at $40{ }^{\circ} \mathrm{C}$ for 20 minutes prior to UV curing.

\section{Curing}

Typically samples were cured from 40 minutes up to 24 hours (depending on the size and thickness) under a UV lamp that consists of $4 \times 18 \mathrm{~W}$ tube (Maplin N29CH), $230 \mathrm{~V}, 50-60 \mathrm{~Hz}$, $365 \mathrm{~nm}$ at ambient temperature. After the UV curing process, the samples were left in a covered Petri dish for 10 days to allow completion of the curing process.

\section{Powdering}

Samples were subjected to grinding in a ball-mill grinder (MiniMill Pulverisette 23 FRITSCH) to ensure uniformity before TGA, DSC, FT-IR and NMR measurements. The average grain size was in the range $24-100 \mu \mathrm{m}$ (Fig. S1 $\dagger$ ).

\section{Resistance to black and grey wastewater}

In order to investigate resistance to grey and black water a number of experiments have been carried out, in which samples were immersed in various buffer solutions $(\mathrm{pH} 4, \mathrm{pH}$ 7, and $\mathrm{pH}$ 10) for 4 weeks. These studies were aimed at examining the behaviour of samples immersed in solutions over a wide range of $\mathrm{pH}$ values (from strongly acidic to alkaline). This choice of $\mathrm{pH}$ values was selected on the basis of international and regional regulations for black and grey water discharges. ${ }^{27}$

\section{UV ageing}

Samples were subjected to UV irradiation for varying periods of time in order to accurately determine the time scales for distinguishing UV curing (polymerisation) and UV ageing processes. The solid samples have also been exposed to UV radiation for $1 \mathrm{~h}, 5 \mathrm{~h}, 24 \mathrm{~h}, 4$ days and 7 days, respectively (Fig. S2†).

\section{Hygrothermal ageing}

In order to investigate the chemistry behind the degradation of the polymer matrix (resin) in the marine environment, a hygrothermal ageing experiment was carried out. The specimens were first dried in the oven at $35{ }^{\circ} \mathrm{C}$, followed by the immersion of the first series of samples in distilled water, employing a constant temperature of $40{ }^{\circ} \mathrm{C}$ for 7 weeks. A second series of samples were immersed in salty water $(3.5 \mathrm{wt} \% \mathrm{NaCl}$ in distilled water $)$ at a constant temperature of $40{ }^{\circ} \mathrm{C}$ for 6 weeks. The salinity level was adjusted to correspond to the average salinity of sea-water and the temperature was chosen on the basis of published literature results ${ }^{8}$ based on the ASTM D5229 standard.

\section{Gravimetric analysis}

The samples were cured in a latex moulding cast of dimensions $2 \times 12 \times 35 \mathrm{~mm}$. It was subsequently dried in an oven at $35{ }^{\circ} \mathrm{C}$ to a constant weight and thereafter immersed in distilled water at $40{ }^{\circ} \mathrm{C}$ for 12 weeks. During this period gravimetric analyses were undertaken. Samples were weighed routinely using Ohaus Explorer Prom EPC114C analytical balance.

The resultant moisture uptake was calculated as follows:

$$
\text { Moisture uptake } \%=\frac{W_{\mathrm{W}}-W_{\mathrm{d}}}{W_{\mathrm{d}}} \times 100
$$

where: $W_{\mathrm{d}}$ - wet sample mass, $W_{\mathrm{w}}$ - dry (reference) sample mass.

\section{Differential scanning calorimetry (DSC)}

DSC analysis was carried out using DSC TA Instruments Auto Q20 with a heating rate $20{ }^{\circ} \mathrm{C} \min ^{-1}$ and a temperature range from $-90{ }^{\circ} \mathrm{C}$ to $300{ }^{\circ} \mathrm{C}$ in an aluminum pan with a lid. The sample weight employed was in the region of 5-15 mg.

\section{Thermogravimetric analysis (TGA)}

TGA analysis was performed in a nitrogen atmosphere using TGA TA Instruments Q50 with a constant heating rate of $20^{\circ} \mathrm{C}$ $\min ^{-1}$ and a temperature range from $25{ }^{\circ} \mathrm{C}$ to $600{ }^{\circ} \mathrm{C}$. The quantity of sample used was in the region of $10-20 \mathrm{mg}$.

\section{Fourier transform infrared spectroscopy (FT-IR)}

Tests have been carried out using a Nicolet iS10 FT-IR Spectrometer from Thermo Scientific.

\section{Solid-state NMR}

The measurements were carried out on a wide-bore Bruker Avance-II spectrometer operating at 14.1 T using ramped cross polarisation. ${ }^{28}$ A contact time of $1.2 \mathrm{~ms}$ and $80 \mathrm{KHz}$ SPINAL64 decoupling during the acquisition period was employed. ${ }^{29}$ The samples (approximately $50 \mathrm{mg}$ ) were packed into $4 \mathrm{~mm}$ zirconium oxide rotors and spun about the magic-angle at $10 \mathrm{KHz}$. Each spectrum is the result of 512 acquisitions. All ${ }^{13} \mathrm{C}$ data were referenced with respect to adamantane. ${ }^{30}$ 


\section{Molecular dynamics simulations}

All calculations were performed on an Intel Xeon E5-1650 CPU using version 12.0 of the AMBER software package. ${ }^{31}$ The ELO monomer was parameterised using antechamber and the GAFF $^{32,33}$ force field. A system containing 144 ELO monomers was created using the PACKMOL ${ }^{34}$ software package. In vacuo calculations were first energy minimized for 5000 steps and then heated gradually to $340 \mathrm{~K}$ for $10 \mathrm{ps}$ in the NVT ensemble and then equilibrated for a further $10 \mathrm{ps}$ at $340 \mathrm{~K}$ before a $100 \mathrm{~ns}$ production run. Calculations in solvent used the TIP $3 \mathrm{P}^{35}$ water model (23 426 molecules) and energy minimized with a restraint of $500 \mathrm{kcal} \mathrm{mol}^{-1} \AA^{-2}$ on the non-water atoms for 5 ps followed by no restraints for 5 ps. The system was then heated to $340 \mathrm{~K}$ over $10 \mathrm{ps}$ in the NVT ensemble and then equilibrated for a further $10 \mathrm{ps}$ at $340 \mathrm{~K}$ in the NPT ensemble before a $100 \mathrm{~ns}$ production run in the NPT ensemble.

The solvated periodic system was constructed by first packing 53 ELO monomers (8851 atoms) into a cube with sides $50 \AA$ in length using the PACKMOL package. Using periodic boundary conditions, this system was then equilibrated in the protocol described above for the non-solvated system in order to obtain a cubic system with a density of $0.95 \mathrm{~g} \mathrm{ml}^{-1}$ (experimental value: $0.95 \mathrm{~g} \mathrm{ml}^{-1}$ ) and sides of length $44 \AA$. The resulting periodic box was then extended to $90 \AA$ in the $z$-axis and PACKMOL was used to add 3400 water molecules (19 051 atoms). The resulting solvated, periodic system was then equilibrated using the scheme used for the solvated system above to obtain a system with a density of $0.98 \mathrm{~g} \mathrm{ml}^{-1}$ before a production run of $5 \mathrm{~ns}$.

\section{Results and discussion}

\section{Durability studies}

In order to correctly predict the lifetime of the composite material, which is technically and economically important, the ageing mechanism needs to be understood. For instance, water uptake not only leads to increase in total mass of the vessel, therefore increasing its resistance, fuel consumption and exhaust emissions ${ }^{36,37}$ but also accelerates degradation of the material, which increases the probability of failure and reduces the service life. ${ }^{38}$

A polymer molecule can adopt many different conformations. Properties of the polymer matrix among others depend on fractional free volume (FFV), in other words on porosity, and therefore potential water molecule penetrability of the material. The impact of water on composite material may be chemical (decomposition caused by hydrolysis leading to chain scission resulting in embrittlement or osmotic cracking) and/or physical (water that enters the specimen cause swelling that creates internal stress resulting in delamination and blistering). ${ }^{39-41}$

In our studies the saturation with distilled water was reached after 36 days with a moisture uptake level of around $6.3 \%$ (see Fig. 2). The corresponding saturation with salty water was after 49 days with a moisture uptake level around 5.4\% (see Fig. 2). In stark contrast to earlier work $^{8}$ no blisters were observed, indicating that these could have previously been caused by delamination of the interface between the resin and the fibres.

The most important transition temperature that defines application of the polymeric material (its working temperature) is the glass transition temperature $\left(T_{\mathrm{g}}\right)$. Below the $T_{\mathrm{g}}$ the polymer matrix is normally elastic, and brittle, above the $T_{\mathrm{g}}$ it exhibits viscoelastic behaviour. Therefore, $T_{\mathrm{g}}$ is an important criteria to a composite engineer influencing the choice of polymeric matrix for a fibre-reinforced composite. The $T_{\mathrm{g}}$ value is directly related to such mechanical properties as strength, hardness, brittleness, volume, and Young's modulus, that the polymer presents at the temperature that it is exposed to. ${ }^{\mathbf{4 2}}$ Polymers that are subject to stress are usually being used at temperatures below their $T_{\mathrm{g}}$ to avoid creep under sustained loads. ${ }^{39}$ This is because the structural capacity becomes less predictable if $T_{\mathrm{g}}$ reduces through a structure's life. It is important from a design perspective to create a material with not only the highest possible $T_{\mathrm{g}}$, but also a stable one to obtain the most versatile product.

The Differential Scanning Calorimetry (DSC) test has been employed in order to investigate possible changes in the $T_{\mathrm{g}}$ caused by different methods of ageing as well as gain more knowledge about the mechanism of hygrothermal ageing of ELO resin. In contrast to the conventional epoxy $\operatorname{resin}^{43}$ the $T_{\mathrm{g}}$ value for the investigated resin remained at the same level (40$46{ }^{\circ} \mathrm{C}$, Fig. 3 and Table S1 $\dagger$ ) despite the different methods of ageing (i.e. UV ageing, hygrothermal ageing in salty water and distilled water) that were employed. These results are particularly noteworthy, as conventional epoxy resins ${ }^{\mathbf{4 4}}$ exhibit a perceptible drop in $T_{\mathrm{g}}$ values by $20{ }^{\circ} \mathrm{C}$, for every $1 \%$ of water adsorbed (up to $7 \%$ moisture content). The noticeable absence in the water crystallization signal (around $0{ }^{\circ} \mathrm{C}$ ) may lead to the hypothesis that the adsorbed water is in some way adsorbed on to the resin (see ESI $\dagger$ ).

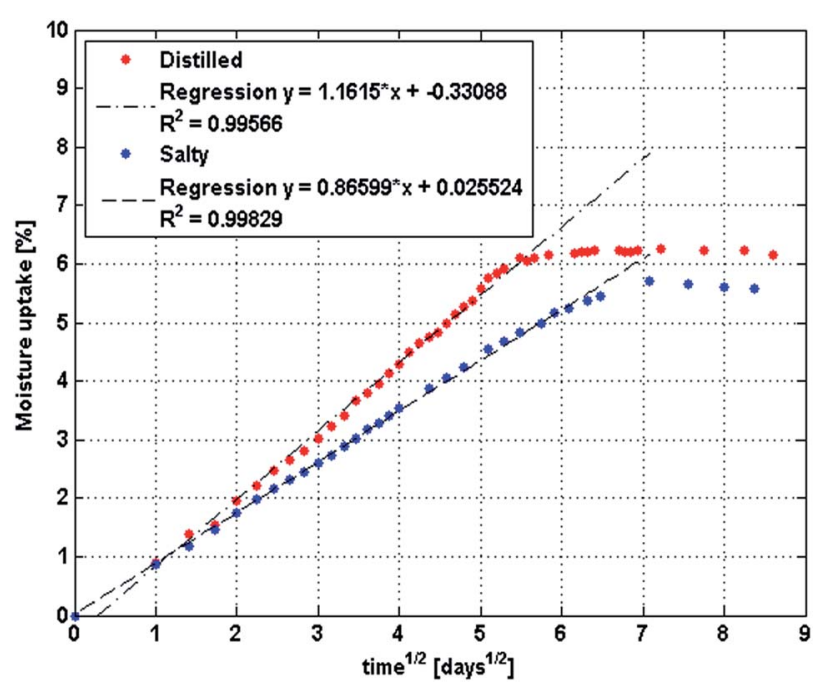

Fig. 2 Gravimetric analysis of a hygrothermally aged resin sample $\left(40{ }^{\circ} \mathrm{C}\right.$; distilled water - red and $3.5 \% \mathrm{NaCl}$ - blue). The dashed lines represent linear regression fit to the first 28 data points. 


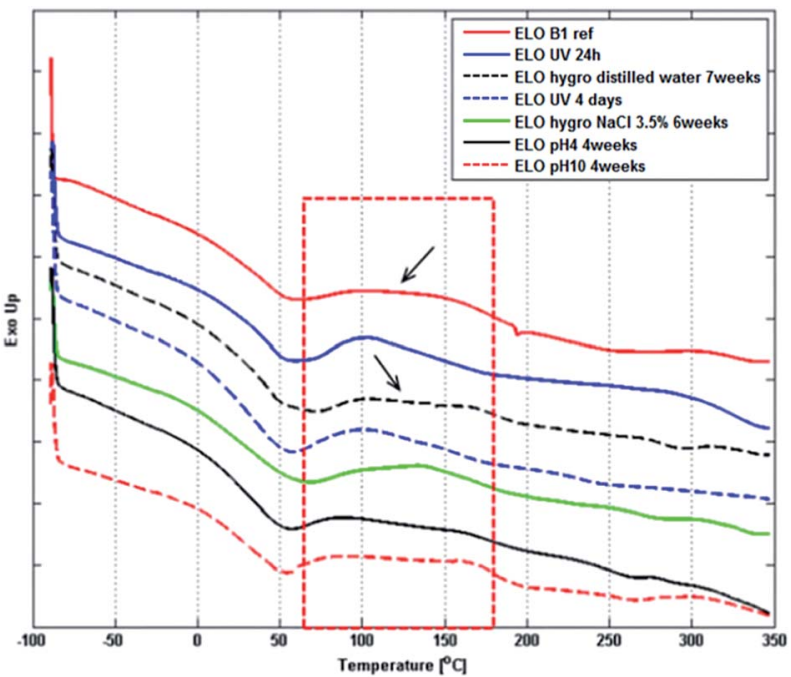

Fig. 3 Differential Scanning Calorimetry (DSC) data showing heat flux as a function of temperature between $-90^{\circ} \mathrm{C}$ and $300^{\circ} \mathrm{C}$. Data for each series has been offset along the vertical axis to highlight the differences and similarities between particular samples.

The region of the plot (presented in Fig. 3) marked with a red dashed rectangle is expected to correspond to the post-curing process. By comparing the results for the reference sample (red line) with the specimen hygrothermally aged at $40{ }^{\circ} \mathrm{C}$ plot (black dashed line) one may notice that after ageing the curve becomes more flat around the glass transition temperature. $\mathrm{Hou}^{45}$ reported that the best mechanical properties for composite consisting of the resin discussed herein and glass fibres have been obtained while curing at an elevated temperature of $37^{\circ} \mathrm{C}$. Our hypothesis is that, when a sample reaches a certain level of polymerisation, remaining free monomers become trapped in the structure, thus losing the ability to move or react. The process of heating up the sample close to its $T_{\mathrm{g}}$ value may restore the mobility of the molecules in the specimen increasing the probability of further polymerisation. To confirm this hypothesis further tests have been conducted and are described in the subsequent sections of this paper.

Thermo-Gravimetric Analysis (TGA) is a widely used tool for assessment of thermal stability and decomposition of polymeric materials at different temperatures. ${ }^{46}$ All the samples employed in this study revealed a similar decomposition pattern, with the only exception being the specimen that was hygrothermally aged in salty water (highlighted in green in Fig. 4). To confirm if the accelerated ageing of salty water specimen had a direct influence on the properties of the resin, further tests are required (see below).

More importantly, the absence of a signal at $100{ }^{\circ} \mathrm{C}$ (Fig. 4) (water evaporation) in all samples further confirms that free water species are not present and is largely consistent with the DSC findings (no free-water was observed in the specimens).

Colin X. et al. ${ }^{47}$ reported that if there are any remaining oxirane rings in an epoxy resin exposed to the water environment, they may undergo reversible hydrolysis, thus contributing to the process of water-trapping and detrapping and

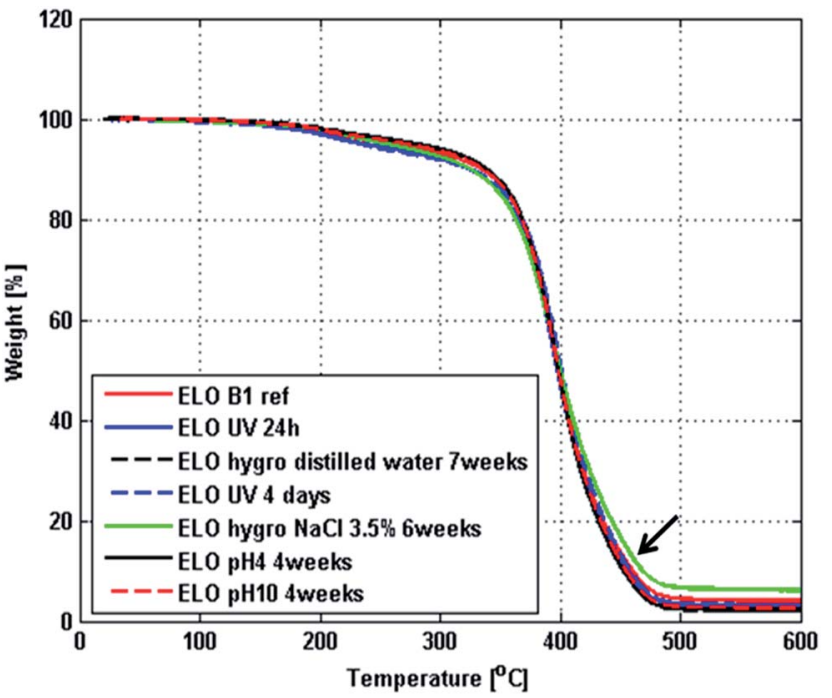

Fig. 4 Thermogravimetric analysis (TGA) data showing weight loss of specimens as a function of temperature between $25^{\circ} \mathrm{C}$ and $600{ }^{\circ} \mathrm{C}$. Note that there is no peak corresponding to water evaporation present and that the only difference in behaviour is observed for sample that has undergone hygrothermal ageing in $\mathrm{NaCl}$ solution (green line).

causing internal stress. This type of ageing is reversible at the atomistic level; however, it may cause irreversible changes at the macroscopic level, affecting long term physical and mechanical performance of the composite material. FT-IR study has been employed in order to investigate the efficiency of curing (conversion of oxirane rings to ether bridges, see Schemes S2 and $\mathrm{S} 3 \dagger$ ), as well as influence of ageing processes on chemistry of resin.

In the IR spectra, it has been observed that after UV curing (Fig. 5 red line) the peak no. 10 in the fingerprint region at around $821 \mathrm{~cm}^{-1}$, which corresponds to the oxirane ring (Table 1), ${ }^{48}$ has been substituted by a noticeable feature at 1066 $\mathrm{cm}^{-1}$ (peak no. 9 in the solid sample that was cured for 3 hours; blue line), that can be attributed to the ether bridge - this unequivocally proves that the curing process has been initiated (Fig. 5). At the same time, it was also observed that the peak no. 7 at $1243 \mathrm{~cm}^{-1}$, which also corresponds to the oxirane ring signature, has not completely disappeared, indicating that the polymerisation process was incomplete and that the resin was not fully cured. It is believed that the remaining oxirane rings contributed via aforementioned mechanism to $5.4-6.3 \%$ water uptake and can partially be responsible for the mechanical testing results reported in the work by Malmstein et al. ${ }^{8}$ For the purpose of calibrating and further optimizing our results, a comparative sample (black line, Fig. 5) was post-cured for an extended period of time (4 days) to ensure a greater degree of polymerisation. It was noteworthy that the additional UV irradiation had no visible effects, when compared with our normal UV-cured ( $3 \mathrm{~h}$ ) sample (blue line, Fig. 5). These findings are in good agreement with TGA and DSC results; but further optimization of the reaction parameters will be required to understand the mechanism and mode of action in greater detail. 


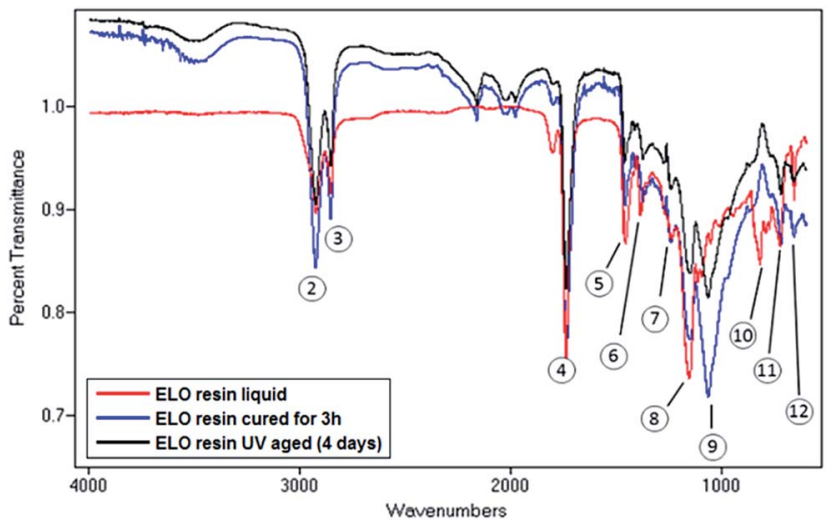

Fig. 5 Comparison of the FT-IR spectra of liquid resin (red), the solid sample that was cured for 3 hours (blue) and solid sample that has been post-cured for additional 4 days (black). Note the partial disappearance of the peaks corresponding to the oxirane rings and the emergence of the ether bridge signature following the curing process (see also Table 1 for chemical assignments).

It has been reported ${ }^{49}$ that conventional epoxy resins are resistant to many chemical substances, especially to alkali. In order to compare the resilience of our sustainable composite resin to black and grey waste, a range of buffer solutions $(\mathrm{pH} 4-$ 10), covering the international rules for black and grey water discharges $(\mathrm{pH} 6-8),{ }^{27}$ were prepared and our solid resin was subjected to exposure periods in this simulated environment for four weeks. It was noteworthy that no significant changes in the physical and chemical properties were observed, when extremities of both acidic and basic $\mathrm{pH}$ environments were applied (Fig. 6).

In order to gain better understanding of the influence of the aforementioned water uptake on the chemistry of the considered resin, hygrothermally aged samples (Fig. 7) have been subject to FT-IR testing. The only difference in the appearance of the spectra of hygrothermally aged specimens that has been observed was the reduction in the intensity of the $659 \mathrm{~cm}^{-1}$ peak (O-H out of plane bend alcohol) (Fig. 7). This result may suggest that resin is chemically stable despite water ingress.

Table 1 Wave numbers of the main peaks observed (by FT-IR) with the resin sample and their corresponding chemical assignments

\begin{tabular}{lll}
\hline No. & Wave number & Chemical assignments \\
\hline 1 & $\sim 3487$ & $\mathrm{OH}$ \\
2 & $\sim 2926$ & Asymmetric C-H stretching of $\mathrm{CH}_{2}, \mathrm{CH}_{3}$ \\
3 & $\sim 2854$ & Symmetric $\mathrm{C}-\mathrm{H}$ stretching of $\mathrm{CH}_{2}, \mathrm{CH}_{3}$ \\
4 & $\sim 1738$ & $\mathrm{O}-\mathrm{C}=\mathrm{O}$ \\
5 & $\sim 1463$ & Scissoring of $\mathrm{CH}_{2}$, asymmetric bending of $\mathrm{CH}_{3}$ \\
6 & $\sim 1374$ & Symmetric bending of $\mathrm{CH}_{3}$ \\
7 & $\sim 1243$ & C-O-C oxirane (epoxy) \\
8 & $\sim 1151$ & C-O stretching of $\mathrm{O}-\mathrm{C}=\mathrm{O}$ \\
9 & $\sim 1066$ & $\mathrm{C}-\mathrm{O}-\mathrm{C}$ ether bridge \\
10 & $\sim 821$ & C-O-C oxirane (epoxy) \\
11 & $\sim 722$ & $(\mathrm{CH})_{n}$ when $n>3$ rocking \\
12 & $\sim 659$ & $\mathrm{O}-\mathrm{H}$ out of plane bend (alcohol)
\end{tabular}

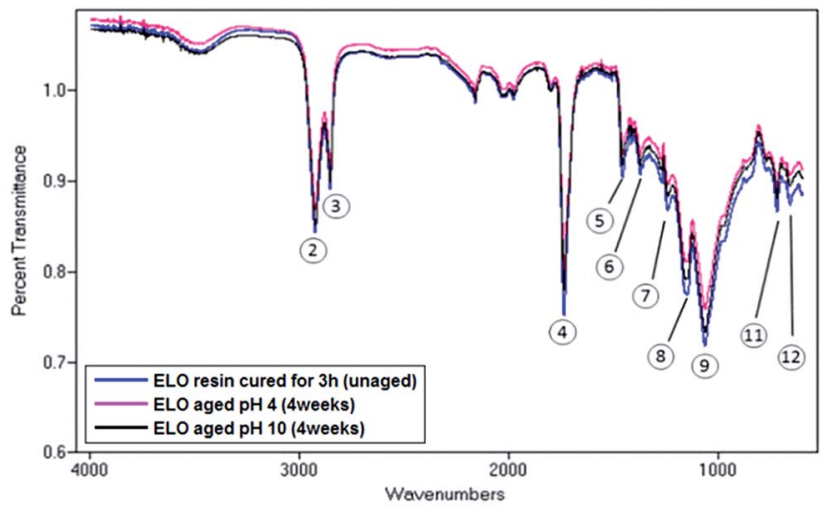

Fig. 6 Comparison of the FT-IR spectra of the UV-cured $(3 \mathrm{~h})$ solid resin (blue line) and its corresponding analogues that were subjected to strongly acidic environment ( $\mathrm{pH} 4$ ) (magenta line) and strongly basic environment ( $\mathrm{pH} 10)$ for 4 weeks (black line).

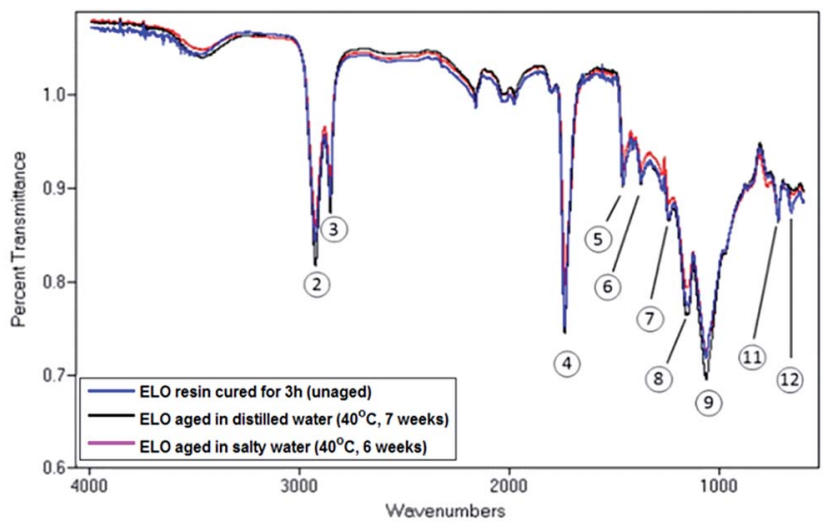

Fig. 7 Comparison of the FT-IR spectra of the UV-cured ( $3 \mathrm{~h}$ ) solid resin (blue line) and its corresponding analogues that were subjected to hygrothermal treatment at $40{ }^{\circ} \mathrm{C}$ in distilled (black line) and salty $(3.5 \% \mathrm{NaCl})$ water (magenta line) for 7 and 6 weeks respectively. Note the highlighted reduction in the intensity of the 12 th peak $(\mathrm{O}-\mathrm{H}$ out of plane bend alcohol).

Solid-state NMR measurements were further employed to corroborate the FT-IR findings: the UV-aged solid polymerised resin and its corresponding analogues that were subjected to hygrothermal treatment in distilled and salty water were evaluated by magic-angle spinning solid-state NMR measurements. Solid-state ${ }^{13} \mathrm{C}$ MAS-NMR showed a consistent chemical structure under the experimental conditions used in this study. The NMR findings are in good agreement with FT-IR results (see Fig. 7 and $c f$. with Fig. 8) and no significant changes in the chemical environments were observed. The peak assignment can be summarized as follows: $\mathrm{CH}_{3}$ groups ( $<20 \mathrm{ppm}$ ), $\mathrm{CH}_{2}$ groups (large signal centred near $30 \mathrm{ppm})$, epoxy groups $(60-85 \mathrm{ppm})$, and ester groups $(173 \mathrm{ppm})$. There is no evidence of different types of carboxylic environments. All the spectra are very similar and consistent with the structure given in Fig. 1. These assignments are in agreement with previous literature. ${ }^{50,51}$ 


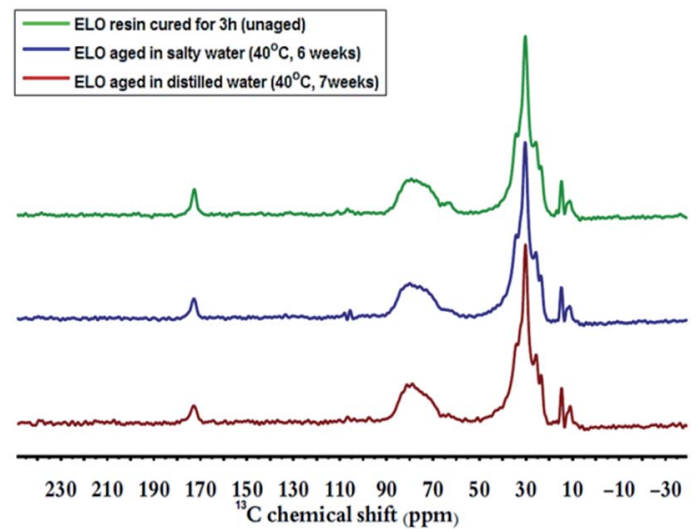

Fig. $8{ }^{13} \mathrm{C}$ NMR spectra recorded at $600 \mathrm{MHz}$ (14.1 Tesla) using a ramped cross polarization sequence, sample spinning at $10 \mathrm{kHz}$ (red - normal UV-polymerized solid resin that was cured for $3 \mathrm{~h}$ with no treatment; green and blue: the solid resin subjected to hygrothermal ageing in $3.5 \% \mathrm{NaCl}$ for 6 weeks and in distilled water for 7 weeks respectively).

Despite the low $T_{\mathrm{g}}$ values, the solid-state resin seems to be chemically stable and this augurs well in terms of future prospects of this material from a chemical standpoint.

\section{Computational simulations}

In order to gain better understanding of the interaction between the polymeric matrix (resin) and the water molecules at the atomic level, Molecular Dynamics (MD) simulations have been performed. A simplified model of the polymerised resin system was constructed by packing 144 ELO monomers to the reported density. ${ }^{52}$ Fig. 9 presents a snapshot of the ELO resin model obtained from an in vacuo molecular dynamics simulation. The cavities that are present in this system have been highlighted. A subsequent simulation in which this structure was solvated shows that it is possible for water

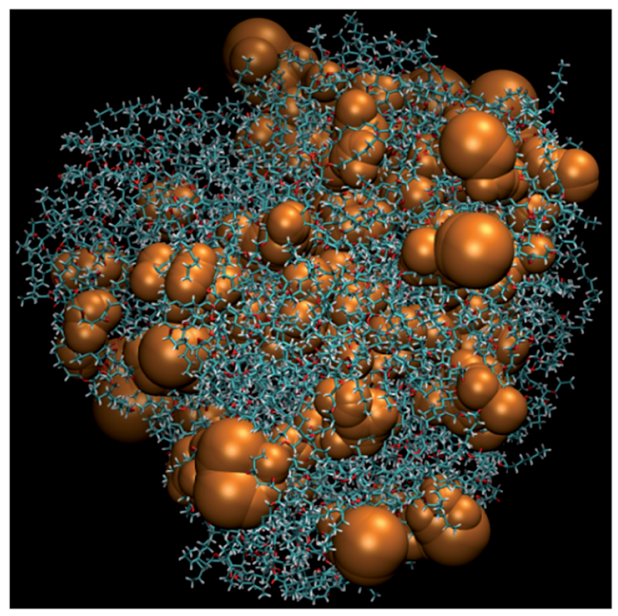

Fig. 9 Snapshot of the ELO resin model from MD simulations (GAFF ${ }^{31,32}$ force field, temperature $340 \mathrm{~K}$, simulation time: $100 \mathrm{~ns}$ ) in vacuum. Cavities that could accommodate water have been highlighted as orange surfaces. molecules to enter into these cavities. This is shown in Fig. 10. However, as the cavities are small, only a small number of water molecules are able to enter each cavity. In order to more accurately represent the interaction of the interface between bulk ELO and water the periodic system shown in Fig. 11 was constructed. It can be seen in this figure that water molecules permeate to a considerable depth into bulk ELO in this more representative system as well. It is expected that the nature of the crosslinking of the monomers during polymerisation will reduce the efficiency of the packing, resulting in even larger cavities. These will likely be capable of containing more water molecules. Despite the fact that the prediction of a polymer structure is a complex task that is outside the remit of this publication and will be approached in future work, these simulations allow us to better understand the mechanism by which water is adsorbed into the resin. Specifically, this process occurs due to the movement of water through the transient pores. This observation highlights the necessity of resin cross-linkage improvement, that would, as a result, lead to reduction of free volume ratio of the matrix and reduction of water uptake.

From an engineering perspective these results are very significant in that they confirm the effects of hygrothermal ageing as measured by moisture absorption and its effect upon the mechanical properties. Without an understanding of the degradation mechanisms involved, the product development required to improve the properties of epoxidised linseed oil based resins to the point where they are commercially viable would largely be trial and error.

\section{Resin modification}

Further to these studies, a preliminary attempt has also been made to improve the properties of the ELO resin by increasing the level of crosslinking. Based on the fact that the resin is cured via photoinitiated cationic polymerisation, it has been established ${ }^{53,54}$ that Brønsted acid sites ${ }^{55}$ play a key role in accelerating rate of cross-linking, and, in order to explore the above hypothesis, we have carried out some initial tests with zeolites,

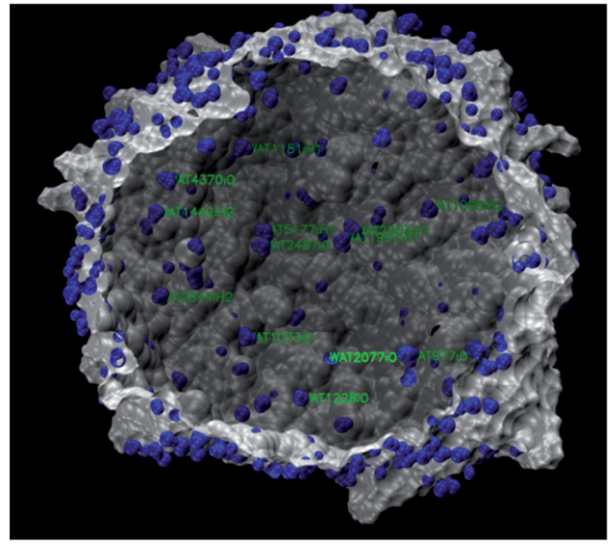

Fig. 10 Snapshot from the MD simulations of the polymerised ELO resin model in water. Water molecules entering the cavities within the polymer are highlighted as blue surfaces. 


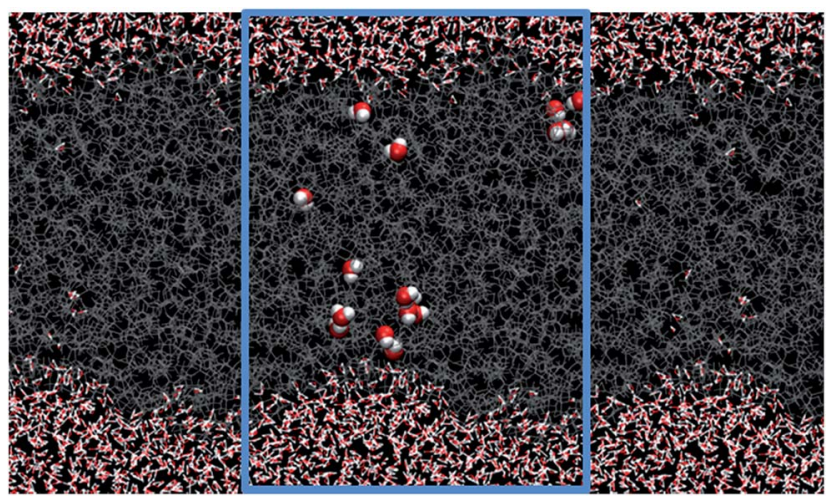

Fig. 11 Snapshot from the periodic MD simulations of the ELO monomers in water, showing water permeation into a periodic slab of ELO. Water molecules that have permeated into the bulk ELO are highlighted. The periodic cell is highlighted with a blue box, but for formatting purposes the image has been truncated in the vertical axis. A non-truncated version of this figure is available in the ESI (Fig. S4†)

which have been industrially-used in the polymer and petrochemical industry as solid-acid catalysts. ${ }^{56,57}$ Zeolites are aluminosilicates, which are composed of alternating $\mathrm{AlO}_{4}$ and $\mathrm{SiO}_{4}$ tetrahedra and possess an overall net-negative charge. In order to compensate for this charge-imbalance and to afford greater stability, charge-compensating cations (such as $\mathrm{H}^{+}$) are utilized, which leads to the origin of strong Brønsted acid sites. With a view to harnessing these Brønsted acid sites to accelerate the cross-linking process, we selected two commercially wellknown zeolites (Zeolite $\mathrm{Y}^{58}$ and ZSM-5), ${ }^{59}$ which are industrially used as heterogeneous solid-acid catalysts, and for sake of comparison, we used a homogeneous sustainable cross-linker (a bio-derived diacid Priopol 1009) ${ }^{25}$ to calibrate and contrast our results. It was noteworthy, from our preliminary tests that

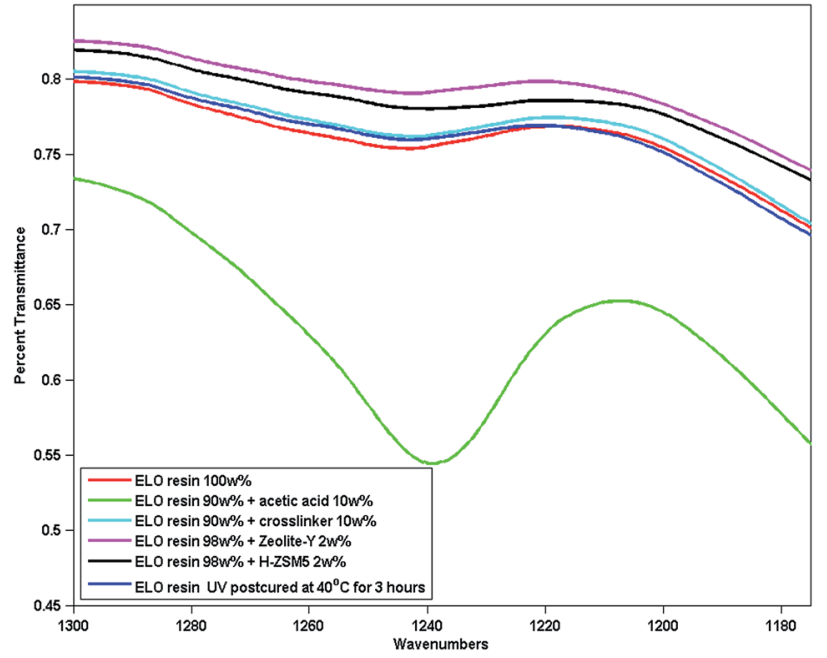

Fig. 12 Comparison of the FT-IR spectra of the UV-cured (3 h) solid resin (red line) and its corresponding analogues that were subjected to modification via addition of acetic acid $10 \mathrm{wt} \%$ (green line), acetic acid 10\% and Pripol 1009 10\% (sky blue line), Zeolite-Y 2\% (magenta blue) and ZSM5 2\% (black line), UV postcuring at the elevated temperature $40{ }^{\circ} \mathrm{C}$ (blue line). the addition of small quantities of the zeolite catalysts (Zeolite Y and ZSM-5) reduces the curing time. The addition of Priopol 1009 did not affect this property, though it visibly increased the elasticity of the sample.

In the IR spectra of the epoxy region, it has been observed that the addition of $2 \mathrm{wt} \%$ of Zeolite $\mathrm{Y}$ and H-ZSM5 had a marked influence on the degree of curing (decrease in the peak intensity around $1239 \mathrm{~cm}^{-1}, \mathrm{C}-\mathrm{O}-\mathrm{C}$ oxirane - (Fig. 12)). In stark contrast, the addition of acetic acid inhibited the curing process (increase of the peak intensity around $1239 \mathrm{~cm}^{-1}$ ).

Those results support our hypothesis that Brønsted acids sites favourably influence the photoinitiated cationic polymerisation (Schemes S2 and S3†), leading to the creation of new crosslinks that are visible as the reduction of the oxirane peak intensity.

It is also worth highlighting that the addition of Pripol 1009 and the introduction of the heterogeneous Zeolite $\mathrm{Y}$ and

(a)

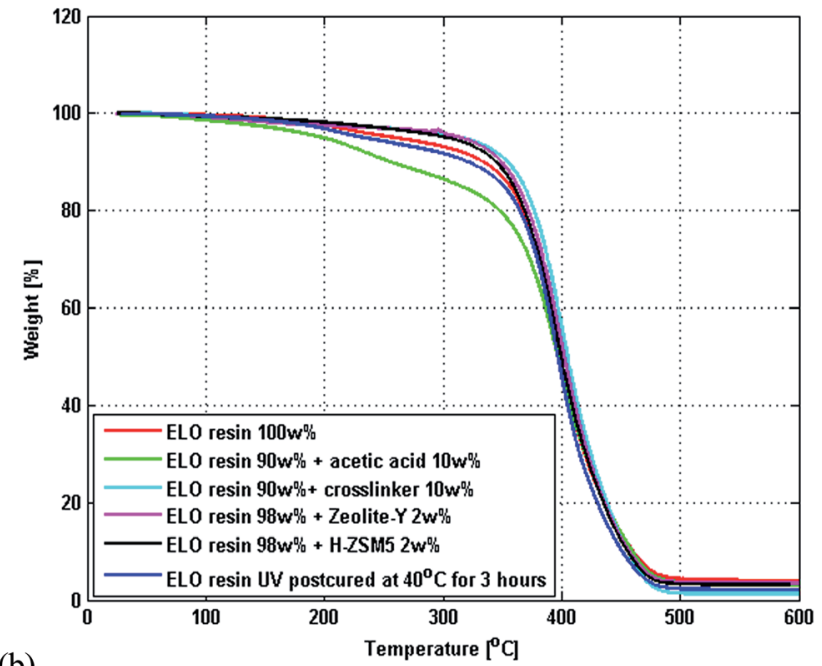

(b)

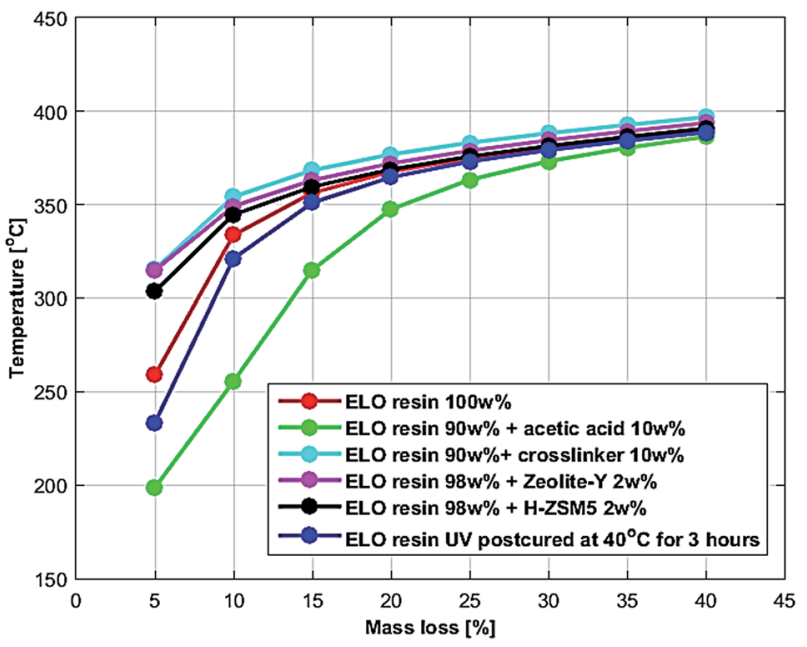

Fig. 13 (a) Thermogravimetric analysis (TGA) data showing weight loss of the specimens as a function of temperature between $25^{\circ} \mathrm{C}$ and $600^{\circ} \mathrm{C}$. Note that a significant difference in behaviour is observed for samples altered by the addition of acetic acid and also with ZSM-5 and Zeolite Y. (b) TGA data showing the mass-loss temperature versus mass-loss for ELO resin with different additives. 
H-ZSM5 catalysts improved the thermal stability of the resin (Fig. 13a and b), in contrast to the addition of acetic acid, which had a detrimental effect. The $T_{\mathrm{d} 5 \%}$ (initial degradation temperature at which $5 \%$ mass loss of the tested sample is observed) for samples with addition of ZSM5, Zeolite Y and crosslinker rose from $258.9{ }^{\circ} \mathrm{C}$ (ELO resin $100 \mathrm{wt} \%$ ) to $303.6{ }^{\circ} \mathrm{C}$, $314.8{ }^{\circ} \mathrm{C}$ and $315{ }^{\circ} \mathrm{C}$ respectively (Fig. 13b). The addition of acetic acid caused a drop of $T_{\mathrm{d} 5 \%}$ to $198.5{ }^{\circ} \mathrm{C}$.

Despite the above modification, the $T_{\mathrm{g}}$ value of the samples remained fairly consistent, with the exception of sample containing acetic acid, which displayed negative change in its behaviour (decrease of the $T_{\mathrm{g}}$ value, which might be connected with lower level of curing) (Fig. 14).

More importantly, the addition of Zeolite-Y, H-ZSM5 and bioderived crosslinker significantly reduced water uptake by $1.5 \mathrm{wt} \%-2 \mathrm{wt} \%$ (Fig. 15). The saturation with distilled water at $40{ }^{\circ} \mathrm{C}$ was reached after 62,38 and 78 days respectively with moisture uptake levels between $4.1 \mathrm{wt} \%-4.6 \mathrm{wt} \%$.

These preliminary results are indeed promising, as they reveal that the importance of water uptake by the polymer matrix, which is a crucial physical property for potential marine application. Furthermore, the thermal stability of the sustainable polymer resin matrix can by suitably improved via dexterous chemical manipulation and modification. The scope for potential expansion involving a range of sustainable cross-linkers and zeolite (and zeotype) ${ }^{\mathbf{6 0 , 6 1}}$ catalysts affords further opportunities for understanding of the chemistry of the resin system and the mechanisms of its degradation at a molecular level, as well as improving the $T_{\mathrm{g}}$, which will lead to a rational design of sustainable composites for future marine application.

Therefore, the possibility of using sustainable heterogeneous solid-acid catalysts ${ }^{62,63}$ to improve the overall efficiency of photoinitiated cationic polymerisation of bioderived epoxy resin systems, might pave the way for future applications within the marine composite industry.

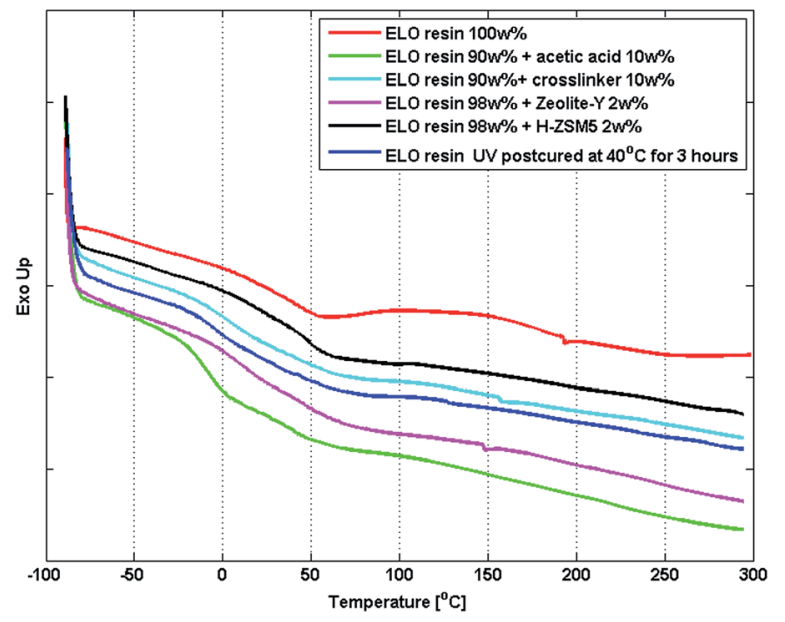

Fig. 14 Differential Scanning Calorimetry (DSC) data showing heat flux as a function of temperature between $-90{ }^{\circ} \mathrm{C}$ and $300{ }^{\circ} \mathrm{C}$. Data for each series has been offset along the vertical axis to highlight the differences and similarities between particular samples.

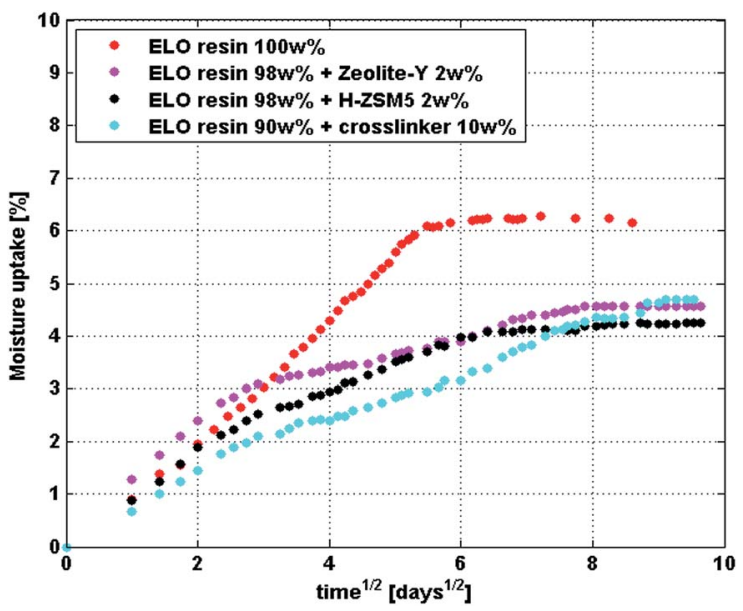

Fig. 15 Gravimetric analysis of a hygrothermally aged $\left(40^{\circ} \mathrm{C}\right.$; distilled water) resin samples with and without the additives showing the positive influence of the additives on resins water resistance.

\section{Conclusions and future prospects}

By using a combination of physico-chemical, gravimetric and spectroscopic characterisation methods, along with molecular dynamics simulations, we have gained preliminary chemical insights on the nature and extent of UV-curing of plant oil based resin and ageing processes in sustainable polymeric composite matrix. The detection of oxirane entities, post-curing, has shed further light on the nature and type of potential active centres that are present and how these are instrumental in initiating chemical degradation processes that are detrimental to the lifetime of the sustainable composite material. It is important to note that the $T_{\mathrm{g}}$ values for the sustainable resin, however low, remained constant post-ageing, in stark contrast to the conventional epoxy materials, thereby highlighting the former's potential advantages for long term marine applications. From an engineering perspective, this finding is important as the designed average life span of components built from such materials is typically around 25 years. ${ }^{64,65}$

The combined spectroscopic approach, which is supported by molecular dynamics simulations, facilitated the detection and location of trapped water molecules, which we believe has a marked impact on the transparency and stiffness of the resulting hygrothermally-aged samples. It was also noteworthy that the addition of zeolite catalysts (ZSM-5 and Zeolite-Y), which possess strong Brønsted acid sites, greatly influenced the level of crosslinking, whilst simultaneously enhancing the thermal stability of the resin, as well as its water resistance. From a maritime engineering perspective, these findings are highly desirable, as they reveal how a dextrous chemical modification at the atomistic level could lead to significant enhancements in the physical properties of the resin. In the long term, these improvements are expected to help reduce the risk of failure of the sustainable composite material, during the service-life of ships and other smaller marine vessels. It is also envisaged that this will simultaneously contribute to increasing the overall fuel efficiency, thereby affording significant environmental benefits. 
This has further highlighted the need for establishing robust structure-property correlations that would enable a more accurate prediction of the average life-span of sustainable composite materials, in our quest for a design-application approach to marine and maritime engineering.

\section{Acknowledgements}

Sustainable Composites and Croda are acknowledged for providing the material. UK Catalysis Hub is kindly thanked for resources and support provided via our membership of the UK Catalysis Hub Consortium and funded by EPSRC (portfolio grants EP/K014714/1, EP/K014706/1, EP/K014668/1, EP/ K014854/1 and EP/K029150/1). We thank Dr Phil Davies (TA Instruments - A division of Waters Ltd) for his consultation over DSC and TGA. Dr Marina Carravetta thanks the Royal Society for a University Research Fellowship. Dr Karl Wilkinson would like to thank the EPSRC for postdoctoral funding (EP/I006613/1) and calculations were performed on the Iridis4 supercomputer of the University of Southampton.

\section{Notes and references}

1 European Comission, End of Life Vehicles (ELVS) Directive 2000/53/EC, Brussels, 2013.

2 United Nations, Kyoto Protocol To the United Nations Framework, Kyoto, 1998.

3 European Comission, Report from the Commission to the European Parliament and the Council Progress Towards Achieving the Kyoto and EU 2020 Objectives, Brussels, 2014.

4 The Chamber of Shipping, Shipping's carbon emissions Design and implementation of market-based measures Part 2: an international GHG contribution fund, London, 2011.

5 Composite Insights, Global Marine Composites Industry 20132018: Trend and Forecast Analysis, Hyderabad, 2013.

6 C. Williams and M. Hillmyer, Polym. Rev., 2008, 48, 1-10.

7 J. Loercks, Polym. Degrad. Stab., 1998, 59, 245-249.

8 M. Malmstein, A. R. Chambers and J. I. R. Blake, Compos. Struct., 2013, 101, 138-143.

9 J. Blake and A. Sobey, ShowBoats International, 2013, 42-48. 10 A. N. Netravali and S. Chabba, Mater. Today, 2003, 6, 22-29.

11 P. Wambua, J. Ivens and I. Verpoest, Compos. Sci. Technol., 2003, 63, 1259-1264.

12 A. O'Donnell, M. Dweib and R. Wool, Compos. Sci. Technol., 2004, 64, 1135-1145.

13 W. Liu, M. Misra, P. Askeland, L. Drzal and A. Mohanty, Polymer, 2005, 46, 2710-2721.

14 J. Zhou and J. P. Lucas, Polymer, 1999, 40, 5513-5522.

15 B. de'Nève and M. Shanahan, Polymer, 1993, 34, 5099-5105. 16 R. L. Shogren, Z. Petrovic, Z. Liu and S. Z. Erhan, J. Polym. Environ., 2004, 12, 173-178.

17 Sustainable Composites Ltd, EcoComp® UV-L resin Material Safety Data Sheet, Redruth, 2009.

18 A. Temiz, G. Kose, D. Panov, N. Terziev, M. H. Alma, S. Palanti and S. Akbas, J. Appl. Polym. Sci., 2013, 130, 1562-1569.
19 P. G. Shende, S. B. Dabhade and Y. D. Phalke, Pigm. Resin Technol., 2004, 33, 85-90.

20 M. Mosiewicki and O. Rojas, Polym. Int., 2007, 56, 875-881.

21 J. Raquez and M. Deléglise, Prog. Polym. Sci., 2010, 35, 487509.

22 V. Sharma and P. P. Kundu, Prog. Polym. Sci., 2006, 31, 9831008.

23 Z. Liu, S. Z. Erhan, D. E. Akin and F. E. Barton, J. Agric. Food Chem., 2006, 54, 2134-2137.

24 N. Boquillon and C. Fringant, Polymer, 2000, 41, 8603-8613.

25 N. Supanchaiyamat, P. S. Shuttleworth, A. J. Hunt, J. H. Clark and A. S. Matharu, Green Chem., 2012, 14, 1759.

26 The Environment Protection Authority South Australia, Managing vessel wastewater for black and/or grey water EPA 709/10, Adelaide, Australia, 2010.

27 W. Chen, Wärtsilä Technical Journal, 2013, 02, 61-65.

28 G. Metz, X. L. Wu and S. O. Smith, J. Magn. Reson., Ser. A, 1994, 110, 219-227.

29 B. Fung, A. Khitrin and K. Ermolaev, J. Magn. Reson., 2000, 142, 97-101.

30 S. Hayashi and K. Hayamizu, Bull. Chem. Soc. Jpn., 1989, 62, 2429-2430.

31 D. A. Case, T. A. Darden, T. E. Cheatham, C. L. Simmerling, J. Wang, R. E. Duke, R. Luo, R. C. Walker, W. Zhang, K. M. Merz, B. Roberts, S. Hayik, A. Roitberg, G. Seabra, J. Swails, A. W. Goetz, I. Kolossváry, K. F. Wong, F. Paesani, J. Vanicek, R. M. Wolf, J. Liu, X. Wu, S. R. Brozell, T. Steinbrecher, H. Gohlke, Q. Cai, X. Ye, J. Wang, M. J. Hsieh, G. Cui, D. R. Roe, D. H. Mathews, M. G. Seetin, R. Salomon-Ferrer, C. Sagui, V. Babin, T. Luchko, S. Gusarov, A. Kovalenko and P. A. Kollman, AMBER 12, University of California, San Francisco, 2012.

32 J. Wang, W. Wang, P. A. Kollman and D. A. Case, J. Mol. Graphics Modell., 2006, 25, 247-260.

33 J. Wang, R. M. Wolf, J. W. Caldwell, P. A. Kollman and D. A. Case, J. Comput. Chem., 2004, 25, 1157-1174.

34 L. Martínez, R. Andrade, E. G. Birgin and J. M. Martínez, J. Comput. Chem., 2009, 30, 2157-2164.

35 W. L. Jorgensen, J. Chandrasekhar, J. D. Madura, R. W. Impey and M. L. Klein, J. Chem. Phys., 1983, 79, 926.

36 A. F. Molland, S. R. Turnock and D. A. Hudson, Ship Resistance and Propulsion, Cambridge University Press, 2011.

37 H. Helms and U. Lambrecht, Int. J. Life Cycle Assess., 2007, 12, 58-64.

38 J. F. W. R. A. Shenoi, Composite Materials in Maritime Structures: Volume 1, Fundamental Aspects, Cambridge University Press, Cambridge, 1993.

39 J. Summerscales, in Durability of Composites in Marine Environment, ed. P. Davies and Y. Rajapakse, Springer, 2014, pp. 1-13.

40 P. Musto, M. Galizia, G. Scherillo and G. Mensitieri, in Durability of Composites in Marine Environment, Springer, 2014, pp. 15-45.

$41 \mathrm{X}$. Colin and J. Verdu, in Durability of Composites in a Marine Environment $S E$ - 3, ed. P. Davies and Y. D. S. Rajapakse, Springer, 2014, pp. 47-114. 
42 J. W. Nicholson, The Chemistry of Polymers, The Royal Society of Chemistry, 2006.

43 ASM International and S. Lampman, in Characterization and Failure Analysis of Plastics, A S M International, 2003, pp. 315-316.

44 W. Wright, Composites, 1981, 12, 201-205.

45 W. Hou, MSc thesis, University of Southampton, 2013.

46 V. Sharma, J. S. Banait, R. C. Larock and P. P. Kundu, J. Polym. Environ., 2010, 18, 235-242.

$47 \mathrm{X}$. Colin and J. Verdu, in Wiley Encyclopedia of Composites, John Wiley \& Sons, Inc., 2011.

48 Encycl. Anal. Chem., ed. J. Coates and R. A. Meyers, 2000, pp. 10815-10837.

49 C. Augustsson, in NM Epoxy Handbook, Nils Malmgren AB, Ytterby, Third edn, 2004, p. 9.

50 M. Stemmelen, F. Pessel, V. Lapinte, S. Caillol, J.-P. Habas and J.-J. Robin, J. Polym. Sci., Part A: Polym. Chem., 2011, 49, 2434-2444.

51 M. Fong and J. Salimon, J. Sci. Tech., 2012, 4, 87-98.

52 Sigma-Aldrich, Epoxidised Linseed Oil MSDS Version 5.3, 2014.

53 Z. Zong, M. D. Soucek, Y. Liu and J. Hu, J. Polym. Sci., Part A: Polym. Chem., 2003, 41, 3440-3456.

54 R. Shah, M. Payne and J. Gale, Int. J. Quantum Chem., 1997, 61, 393-398.
55 M. Potter, D. Sun and E. Gianotti, Phys. Chem. Chem. Phys., 2013, 15, 13288-13295.

56 T. F. Degnan, Top. Catal., 2000, 13, 349-356.

57 H. Hattori and Y. Ono, in Solid Acid Catalysis: From Fundamentals to Applications, Pan Stanford, 2015, p. 15.

58 W. Lutz, Adv. Mater. Sci. Eng., 2014, 2014, 1-20.

59 V. van Speybroeck, K. de Wispelaere, J. van der Mynsbrugge, M. Vandichel, K. Hemelsoet and M. Waroquier, Chem. Soc. Rev., 2014, 43, 7326-7357.

60 E. Gianotti, M. Manzoli, M. E. Potter, V. N. Shetti, D. Sun, J. Paterson, T. M. Mezza, A. Levy and R. Raja, Chem. Sci., 2014, 5, 1810.

61 M. E. Potter, A. J. Paterson, B. Mishra, S. D. Kelly, S. R. Bare, F. Cora, A. B. Levy and R. Raja, J. Am. Chem. Soc., 2015, 137, 8534-8540.

62 M. E. Potter, M. E. Cholerton, J. Kezina, R. Bounds, M. Carravetta, M. Manzoli, E. Gianottii, M. Lefenfeld and R. Raja, ACS Catal., 2014, 4, 4161-4169.

63 R. Raja, M. E. Potter and S. H. Newland, Chem. Commun., 2014, 50, 5940-5957.

64 P. D. de Laszlo, in Fishing Boats of the World, ed. J. O. Traung, Fishing News (Books) Ltd, London, 2nd edn, 1967, p. 199.

65 R. J. Scott, Fiberglass Boat Design and Construction, The Society of Naval Architects and Marine Engineers, New Jersey, Second edn, 1996. 